\title{
New editorial board 2015-2017
}

\author{
Tetsuro Matsuzawa
}

Published online: 25 December 2014

(C) Japan Monkey Centre and Springer Japan 2014

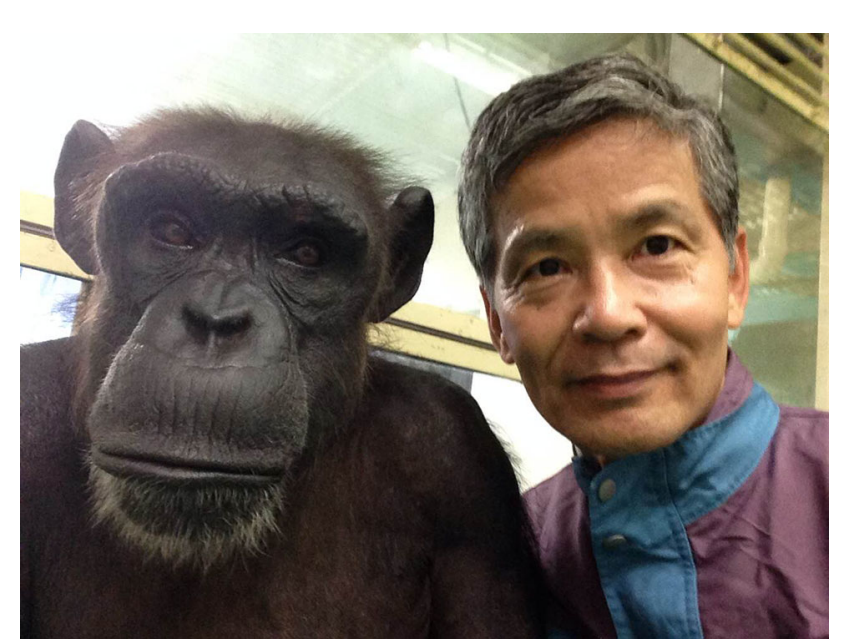

In my capacity as the new Editor-in-Chief, I would like to announce that the new editorial board of the journal Primates comes into effect in January 2015 and will operate for the next 3 years. Primates is the oldest English-language primatology journal in the world, published by the Japan Monkey Centre (JMC) through Springer in collaboration with the Primate Society of Japan. The former Editor-in-Chief, Juichi Yamagiwa, was recently elected as the 26th president of Kyoto University, and to replace him I have taken on the role of Editor-in-Chief from October 2014. I appreciate all the efforts of my colleagues who act as associate editors and advisory board members, without whom the journal could not achieve its aims. Please allow

T. Matsuzawa

Japan Monkey Centre, Inuyama, Japan

T. Matsuzawa $(\square)$

Kyoto University, Inuyama, Japan

e-mail: matsuzawa.tetsuro.8w@kyoto-u.ac.jp me to take this opportunity to look back over our history. Primatology in Japan began on December 3rd, 1948. It was on that day that the late Kinji Imanishi (1902-1992) and his two undergraduate students from Kyoto University set out for Koshima Island to observe wild Japanese monkeys. By studying the social behavior of the monkeys they aimed to understand the evolutionary origins of human society. Primatology is the scientific study of all primates, including humans. In order to understand ourselves as humans, it is essential to study our closest living relatives; an interest in apes, monkeys, and prosimians is shared by scientists and laypeople alike. Japanese primatologists worked together to help create JMC, founded on October 17th, 1956. Soon thereafter, in 1958, JMC sent the first expedition to Africa to study wild gorillas and chimpanzees. JMC aims to promote research, education, conservation, welfare, and communication to the public regarding nonhuman primates. JMC became a Public Interest Incorporated Foundation from April 2014 and is a registered museum responsible for producing the journal Primates. It also runs a unique zoo, specializing in nonhuman primates, housing about 1,000 individuals representing 67 different species. Please visit the following website to learn more: http://www.japan monkeycentre.org/. Through the scientific study of nonhuman primates we can develop a better appreciation of our own place within nature.

Tetsuro Matsuzawa

Editor-in-Chief, Primates,

General Director, Japan Monkey Centre

Professor, Kyoto University 